\title{
Auscultatory Blood Pressure Monitor
}

National Cancer Institute

\section{Source}

National Cancer Institute. Auscultatory Blood Pressure Monitor. NCI Thesaurus. Code C69318.

An instrument for blood pressure monitoring consisting of a sphygmomanometer and a stethoscope to hear blood flow. 